\title{
High temperature cyclic oxidation and hot corrosion behaviours of superalloys at $900^{\circ} \mathrm{C}$
}

\author{
SUBHASH KAMAL, R JAYAGANTHAN* and S PRAKASH \\ Department of Metallurgical and Materials Engineering, Indian Institute of Technology Roorkee, \\ Roorkee 247 667, India
}

MS received 20 June 2008; revised 17 May 2010

\begin{abstract}
Oxidation and hot corrosion are serious problems in aircraft, marine, industrial, and land-base gas turbines. It is because of the usage of wide range of fuels coupled with increased operating temperatures, which leads to the degradation of turbine engines. To obviate these problems, superalloys, viz. Superni 75 , Superni 718 and Superfer $800 \mathrm{H}$ superalloys (Midhani grade), are the prominent materials for the high temperature applications. It is very essential to investigate the degradation mechanism of superalloys due to oxidation and hot corrosion and substantiate the role of alloying elements for the formation of protective oxide films over the surface of the superalloys. Therefore, the present work investigates the oxidation and hot corrosion behaviour of superalloys exposed to air and molten salt $\left(\mathrm{Na}_{2} \mathrm{SO}_{4}-60 \% \mathrm{~V}_{2} \mathrm{O}_{5}\right)$ environment, respectively, at $900^{\circ} \mathrm{C}$ under cyclic conditions. The weight change measurements made on the superalloys during the experiments are used to determine the kinetics of oxidation and hot corrosion. X-ray diffraction (XRD), X-ray mapping and field emission scanning electron microscope (FESEM, FEI, Quanta 200F company) with EDAX Genesis software attachment, made in Czech Republic are used to characterize the corroded products of the superalloys. It is observed that the formation of scale rich in $\mathrm{Cr}_{2} \mathrm{O}_{3}, \mathrm{NiO}$ and spinel $\mathrm{NiCr}_{2} \mathrm{O}_{4}$ has contributed for the better oxidation and hot corrosion resistance of Superni 75; whereas relatively lesser hot corrosion resistance of Superfer $800 \mathrm{H}$ is due to the formation of non-protective oxides of iron and sulphides of iron and nickel. The parabolic rate constants calculated for the superalloys show that the corrosion rate is minimum in air as compared to molten salt environment.
\end{abstract}

Keywords. Oxidation; hot corrosion; superalloys.

\section{Introduction}

Degradation by high-temperature oxidation, hot corrosion, and erosion are the main failure modes of components in the hot sections of gas turbines, boilers, industrial waste incinerators, metallurgical furnaces, petrochemical installations, etc. Superalloys have been developed for high temperature applications, but they are not able to meet the requirements of both the high-temperature strength and the high-temperature erosion-corrosion resistance simultaneously (Sidhu et al 2006). Superalloys find their largest application in the gas turbine industry, constituting over $50 \%$ of the gas turbine weight due to their good mechanical properties at elevated temperatures (Zhang et al 1993; Chen et al 1995; Li and Wahi 1995; Wang et al 1995). These superalloys exhibit superior mechanical strength, surface stability, creep and fatigue resistance at high temperature (Maledi et al 2006). The turbine engines are exposed to extremely high temperature and harsh environment and therefore, tend to suffer from significant

\footnotetext{
*Author for correspondence (rjayafmt@iitr.ernet.in)
}

material degradation during service (Bettge et al 1995; Esmaeili et al 1995). Today, numerous $\mathrm{Ni}-, \mathrm{Co}-$, and Fe-based superalloys serve in all kinds of gas turbine engine applications. Low-grade fuel oils and fossil fuels used in energy generation systems contains complex mixtures of molten sodium sulfate $\left(\mathrm{Na}_{2} \mathrm{SO}_{4}\right)$ and vanadium pentoxide $\left(\mathrm{V}_{2} \mathrm{O}_{5}\right)$ (Deb et al 1996; Rocca et al 2003). The $\mathrm{Na}_{2} \mathrm{SO}_{4}$ can be ingested in the turbine intake air or it can be produced by a reaction between sodium chloride $(\mathrm{NaCl})$ ingested with the intake air and sulfur impurities in the fuel (Stringer 1976). Vanadium is present in the fuel in the form of vanadium porphyrin, which transforms during combustion into $\mathrm{V}_{2} \mathrm{O}_{5} . \mathrm{V}_{2} \mathrm{O}_{5}$ and $\mathrm{Na}_{2} \mathrm{SO}_{4}$ form low melting point inorganic compounds, which undergoes eutectic reaction below $600^{\circ} \mathrm{C}$. When the temperature exceeds melting point of the deposits (Hejwowski 2006), these compounds start slowly depositing on the turbine blades, consequently corrosion rate rapidly increases due to faster transport phenomena in liquid phase which causes catastrophic corrosion phenomena (Otero et al 1996). Hence, for efficient functioning of gas turbine components, it is highly essential to develop superalloys with high-temperature strength as well as good hot corro- 
sion resistance (Gurrappa 1999). However, there is still a lack of basic understanding of how these superalloys behave in severe $\left(\mathrm{Na}_{2} \mathrm{SO}_{4}-60 \% \mathrm{~V}_{2} \mathrm{O}_{5}\right)$ operating environment. Therefore, the oxidation and hot corrosion behaviour of nickel-based and iron-based superalloys have been investigated at $900^{\circ} \mathrm{C}$ in air with or without $\mathrm{Na}_{2} \mathrm{SO}_{4}-60 \% \mathrm{~V}_{2} \mathrm{O}_{5}$ coatings on the superalloy specimens in the present work. The kinetics of corrosion of superalloy substrates was determined from the weight change of the samples calculated during the experiments. XRD, SEM and FE-SEM/EDAX, and X-ray mapping were used to characterize the corrosion products in order to render an insight into the corrosion mechanisms.

\section{Experimental}

\subsection{Substrate material}

The Ni- and Fe-based substrate materials selected for this study, viz. Superni 75, Superni 718 and Superfer 800H, were provided by Mishra Dhatu Nigam Limited, Hyderabad (India) in the rolled sheet form. The nominal chemical composition of the substrate materials is reported in table 1 .

\subsection{Substrate preparation}

The specimens, with dimensions of $\sim 20 \times 15 \times 5 \mathrm{~mm}^{3}$, were cut from the alloy sheets of superalloys, Superni 75, Superni 718 and Superfer $800 \mathrm{H}$. The specimens were polished using emery papers of 220, 400, 600 grit sizes and subsequently on $1 / 0,2 / 0,3 / 0$ and $4 / 0$ grades. Final polishing was carried out on a cloth polishing wheel machine with $1 \mu \mathrm{m}$ alumina powder suspension. Subsequently the specimens were washed properly, cleaned with acetone and dried in hot air to remove any moisture.

\subsection{Air and molten salt corrosion test}

Cyclic studies were performed for the superalloy substrates in molten salt environments $\left(\mathrm{Na}_{2} \mathrm{SO}_{4}-60 \% \mathrm{~V}_{2} \mathrm{O}_{5}\right)$ and in air for 100 cycles. Each cycle consisted of $1 \mathrm{~h}$ of heating at $900^{\circ} \mathrm{C}$ in a silicon carbide tube furnace followed by $20 \mathrm{~min}$ of cooling at room temperature. The purpose of imposing cyclic conditions was to create an accelerated environment as observed in real cases for hot corrosion testing. The specimens were mirror polished down to $1 \mu \mathrm{m}$ alumina on a cloth-polishing wheel before the corrosion run. A coating of uniform thickness with $3-5 \mathrm{mg} / \mathrm{cm}^{2}$ of $\left(\mathrm{Na}_{2} \mathrm{SO}_{4}-60 \% \mathrm{~V}_{2} \mathrm{O}_{5}\right)$ was applied with a camel hair brush on the preheated sample $\left(250^{\circ} \mathrm{C}\right)$. The weight change measurements were taken at the end of each cycle using an electronic balance machine (model 06120 , Contech) with a sensitivity of $1 \mathrm{mg}$. The spalled scale was also included at the time of measurement of the weight change to determine the total rate of corrosion. The kinetics of corrosion was analysed from the results of weight change measurements. The samples after oxidation and hot corrosion were analysed by XRD for the phase identification and FE-SEM/EDAX for surface morphological and compositional analysis and X-ray mapping for cross sectional compositional analysis.

\section{Results}

\subsection{Visual observations}

The superalloys during hot corrosion in the molten salt environment at $900^{\circ} \mathrm{C}$ have shown spalling/sputtering right from the initial few cycles which intensified with the progress of study with lot of corrosion products formed in the boat. The surface became rougher with progressive exposure of time with a uniform pitting observed throughout the surface of the samples. A greenish scale appeared on the surface of Superni 75 and Superfer $800 \mathrm{H}$ (figures la and c); during initial cycles, the colour was dark grey which turned greenish with grey patches. Superni 718 (figure 1b) in molten salt environment has shown spalling/sputtering behaviour from the 5th cycle, during initial cycles the colour of the scale was dark grey which turned into brownish with light grey patches around it.

Colour of oxide scale formed on the superalloys, Superni 75, Superni 718 and Superfer 800H, after air oxidation for 100 cycles at $900^{\circ} \mathrm{C}$ (figures $1 \mathrm{~d}$, e and f), was dark grey. During initial cycles, light lustrous scale formed, but towards the end of cycles, some greenish tinges were observed on the surface of Superni 75 (figure 1d) along with a few white spots. A mixture of dark and light grey scale formed on the surface of Superni 718 (figure 1e) along with brownish grey scale appearing at

Table 1. Chemical composition of substrate material.

\begin{tabular}{lccccccccccc}
\hline & \multicolumn{10}{c}{ Chemical composition (wt \%) } \\
\cline { 2 - 11 } Alloy midhani grade (similar grade) & $\mathrm{Fe}$ & $\mathrm{Ni}$ & $\mathrm{Cr}$ & $\mathrm{Ti}$ & $\mathrm{Al}$ & $\mathrm{Mo}$ & $\mathrm{Mn}$ & $\mathrm{Si}$ & $\mathrm{Cu}$ & $\mathrm{Ta}$ & $\mathrm{C}$ \\
\hline Superni 75 (Nimonic 75) & $3 \cdot 0$ & $77 \cdot 1$ & $19 \cdot 5$ & $0 \cdot 3$ & & & & & \\
Superni 718 (Inconel 718) & $18 \cdot 5$ & $52 \cdot 37$ & $19 \cdot 0$ & $0 \cdot 9$ & $0 \cdot 5$ & $3 \cdot 05$ & $0 \cdot 18$ & $0 \cdot 18$ & $0 \cdot 15$ & $5 \cdot 13$ & $0 \cdot 04$ \\
Superfer 800H (Incoloy 800H) & $43 \cdot 8$ & $32 \cdot 0$ & $21 \cdot 0$ & $0 \cdot 3$ & $0 \cdot 3$ & & $1 \cdot 5$ & $1 \cdot 0$ & & & $0 \cdot 1$ \\
\hline
\end{tabular}



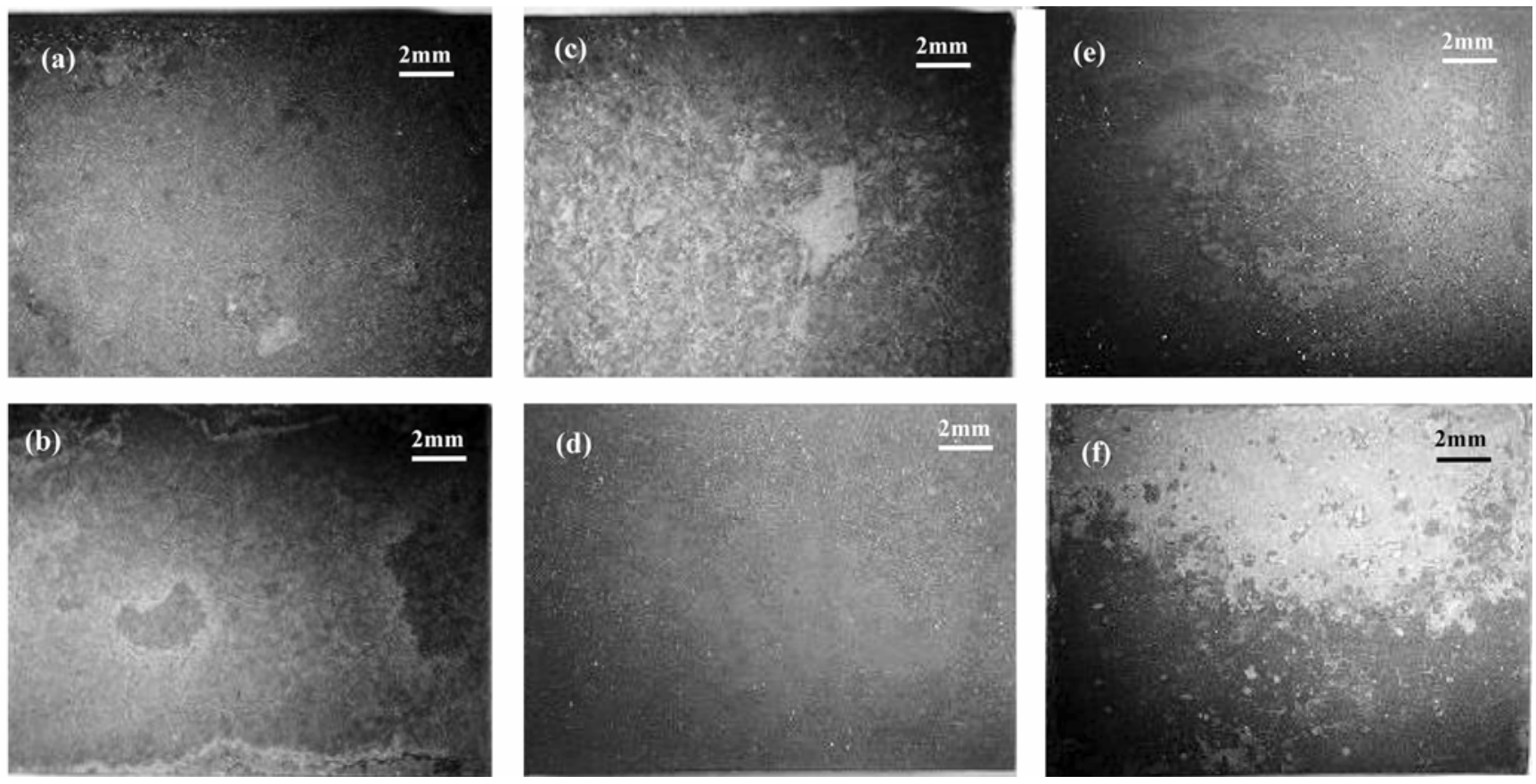

Figure 1. Surface macrographs of superalloys subjected to hot corrosion and oxidation in $\mathrm{Na}_{2} \mathrm{SO}_{4}-60 \% \mathrm{~V}_{2} \mathrm{O}_{5}$ and air environment at $900^{\circ} \mathrm{C}$ for 100 cycles: (a) and (d) Superni 75, (b) and (e) Superni 718 and (c) and (f) Superfer 800H, respectively.

the edges with a few white spots. However, in case of Superfer $800 \mathrm{H}$ (figure 1f), the oxide scale shows two regions, with dark and light grey scales, where the random distribution of dark grey scale with brownish tinges is observed.

\subsection{Cyclic oxidation and hot corrosion}

Figure 2 shows the weight gain/unit area for the air and molten salt $\left(\mathrm{Na}_{2} \mathrm{SO}_{4}-60 \% \mathrm{~V}_{2} \mathrm{O}_{5}\right)$ environment, respectively, for the superalloys subjected to $900^{\circ} \mathrm{C}$ for 100 cycles. In molten salt environment, superalloy, Superfer $800 \mathrm{H}$, shows a higher weight gain as compared to Superni 75 and Superni 718, also in air environment. Superfer $800 \mathrm{H}$ shows higher weight as compared with Superni 75 and Superni 718 . Whereas Superni 718 in molten salt $\left(\mathrm{Na}_{2} \mathrm{SO}_{4}-60 \% \mathrm{~V}_{2} \mathrm{O}_{5}\right)$ environment has shown a parabolic behaviour up to 25th cycle, thereafter spalling/sputtering intensified with some of the corrosion products starting to fall outside the boat which continued up to 70th cycle. After 70th cycle, the weight gain by the sample ceased and it was difficult to measure accurate weight gain. The weight gain data reveals that the Superni 75 was found to be more hot corrosion resistant than the Superfer $800 \mathrm{H}$ and Superni 718 superalloys. The air oxidized superalloy, Superni 718, has shown least weight gain than that of Superni 75 and Superfer $800 \mathrm{H}$.

The weight gain square $\left(\mathrm{mg}^{2} / \mathrm{cm}^{4}\right)$ vs time (number of cycles) plots are shown in figure 2 to establish the rate law for the hot corrosion. It is observed from the graph that all the superalloys follow nearly parabolic rate law. The parabolic rate constant, $K_{\mathrm{p}}$, was calculated by a linear least-square algorithm to a function in the form of

$$
(W / A)^{2}=K_{\mathrm{p}} t,
$$

where $W / A$ is the weight gain per unit surface area $\left(\mathrm{mg} / \mathrm{cm}^{2}\right)$ and $t$ indicates the number of cycles representing the time of exposure. The parabolic rate constants for superalloys in air and molten salt environment $\left(\mathrm{Na}_{2} \mathrm{SO}_{4}{ }_{-}^{-}\right.$ $60 \% \mathrm{~V}_{2} \mathrm{O}_{5}$ ) were calculated on the basis of 100 cycles data and are reported in table 2. Figure 3 shows the cumulative weight gain per unit area for the superalloys in air and molten salt environment.

\subsection{X-ray diffraction analysis (XRD) of scale}

The XRD patterns for the superalloys is subjected to molten salt $\left(\mathrm{Na}_{2} \mathrm{SO}_{4}-60 \% \mathrm{~V}_{2} \mathrm{O}_{5}\right)$ environment at $900^{\circ} \mathrm{C}$ after 100 cycles. The major phases identified for Superni 75 are $\mathrm{NiO}, \mathrm{TiO}_{2}, \mathrm{NiFe}_{2} \mathrm{O}_{4}, \mathrm{Cr}_{2} \mathrm{O}_{3}, \mathrm{Ni}\left(\mathrm{VO}_{3}\right)_{2}, \mathrm{~V}_{2} \mathrm{O}_{4}$ and $\mathrm{NiCr}_{2} \mathrm{O}_{4}$, whereas in the scale of Superni 718, an additional phase, $\gamma-\mathrm{Fe}_{2} \mathrm{O}_{3}$ except $\mathrm{V}_{2} \mathrm{O}_{4}$ is noticed. Similarly, for Superfer $800 \mathrm{H}$, the scale has all the above phases, but without $\mathrm{V}_{2} \mathrm{O}_{4}$.

\section{$3.4 \quad F E-S E M / E D A X$ analysis of scale}

3.4a Surface morphology of scale: FE-SEM/EDAX micrographs with EDS spectrum of the superalloy speci- 


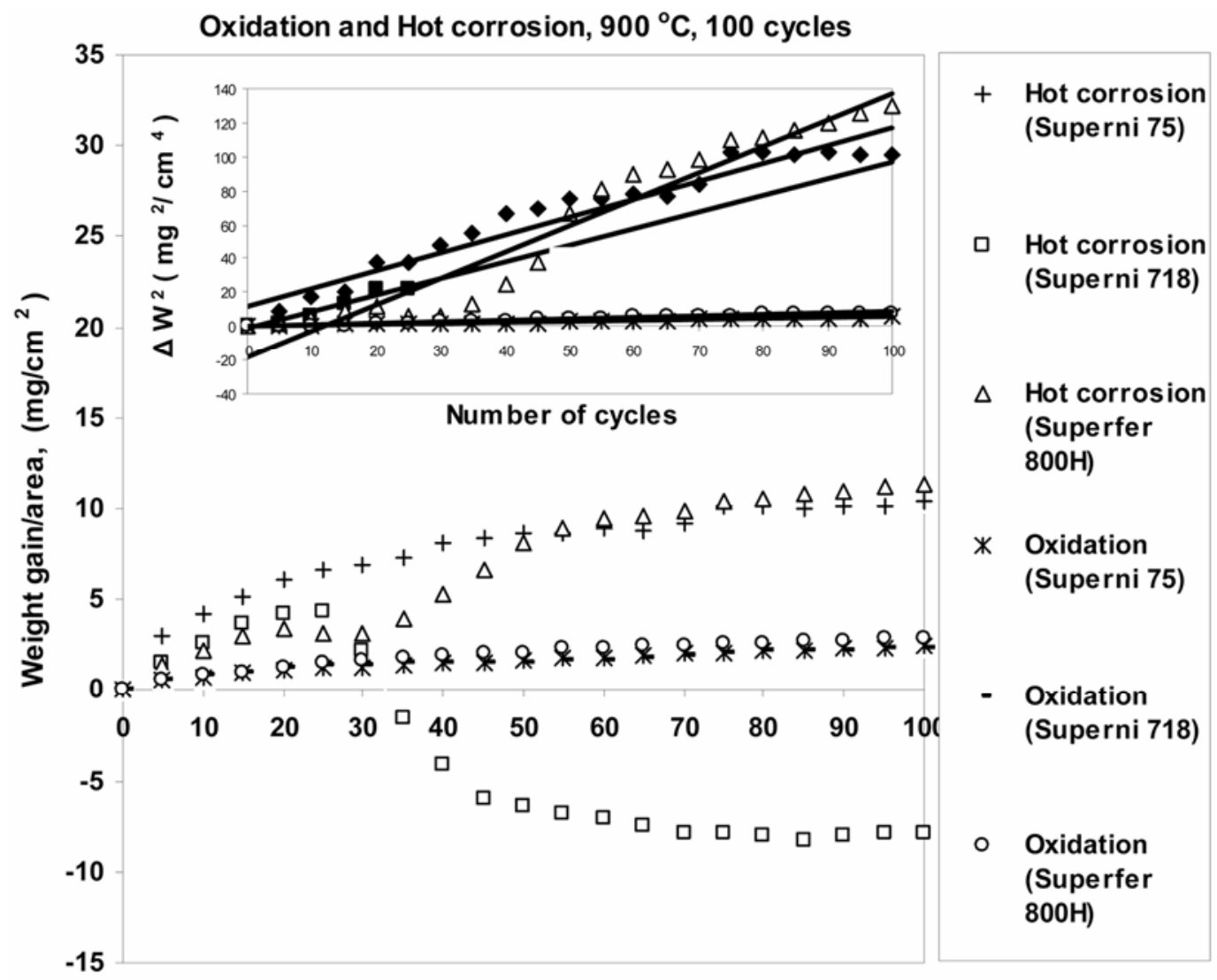

Number of cycles

Figure 2. Weight gain/area vs number of cycles plot for superalloys subjected to cyclic oxidation and hot corrosion for 100 cycles at $900^{\circ} \mathrm{C}$. Insert is fitted for (weight gain/area) ${ }^{2}$ vs number of cycles.

Table 2. Values of parabolic rate constant, $k_{\mathrm{p}}$.

\begin{tabular}{lcc}
\hline & \multicolumn{2}{c}{ Parabolic rate constants $\left(k_{\mathrm{p}}\right)\left(10^{-10} \mathrm{~g}^{2} \mathrm{~cm}^{-4} \mathrm{~s}^{-1}\right)$} \\
\cline { 2 - 3 } Superalloys & Oxidation & Hot corrosion \\
\hline Superni 75 & $0 \cdot 16$ & $2 \cdot 29$ \\
Superni 718 & $0 \cdot 147$ & $2 \cdot 1$ \\
Superfer 800H & 0.237 & $4 \cdot 312$ \\
\hline
\end{tabular}

mens after cyclic oxidation in air and hot corrosion in molten salt $\left(\mathrm{Na}_{2} \mathrm{SO}_{4}-60 \% \quad \mathrm{~V}_{2} \mathrm{O}_{5}\right)$ environment for 100 cycles at $900^{\circ} \mathrm{C}$ are shown in figures 4 and 5 , respectively. Air oxidized superalloys clearly indicate the formation of $\mathrm{NiO}$ as a major oxide phase formed on Superni 75 (figure 4a); but in case of Superni 718 (figure $4 \mathrm{~b}), \mathrm{Cr}_{2} \mathrm{O}_{3}$ is the major oxide phase formed on the air oxidized surface. In Superfer $800 \mathrm{H}$ (figure 4c), the formation of hemispherical shaped protrusion was observed, which mainly consists of $\mathrm{Fe}_{2} \mathrm{O}_{3}, \mathrm{MnO}$ and $\mathrm{Cr}_{2} \mathrm{O}_{3}$ as the predominant phases. All the three hot corroded superalloys in molten salt $\left(\mathrm{Na}_{2} \mathrm{SO}_{4}-60 \% \mathrm{~V}_{2} \mathrm{O}_{5}\right)$ environment show the oxide scales of three different chemical compositions on the surface. For example, superalloy Superni

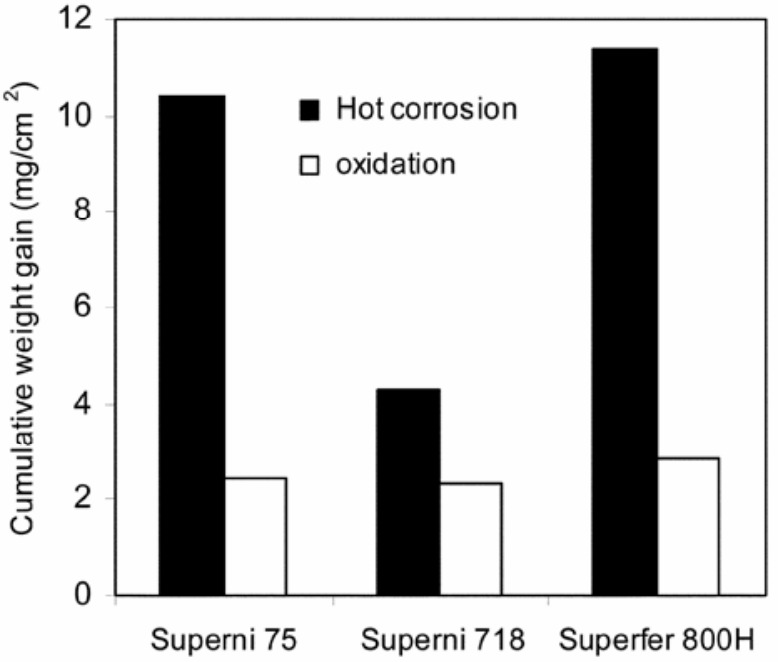

Figure 3. Bar chart showing cumulative weight gain per unit area for the superalloys subjected to cyclic oxidation and hot corrosion for 100 cycles at $900^{\circ} \mathrm{C}$.

75 (figure 5a) shows $\mathrm{NiO}(96 \%)$ in the form of fine irregular shaped crystals as a predominant phase, but superalloy, Superfer $800 \mathrm{H}$ and Superni 718 (figures 5(b) 

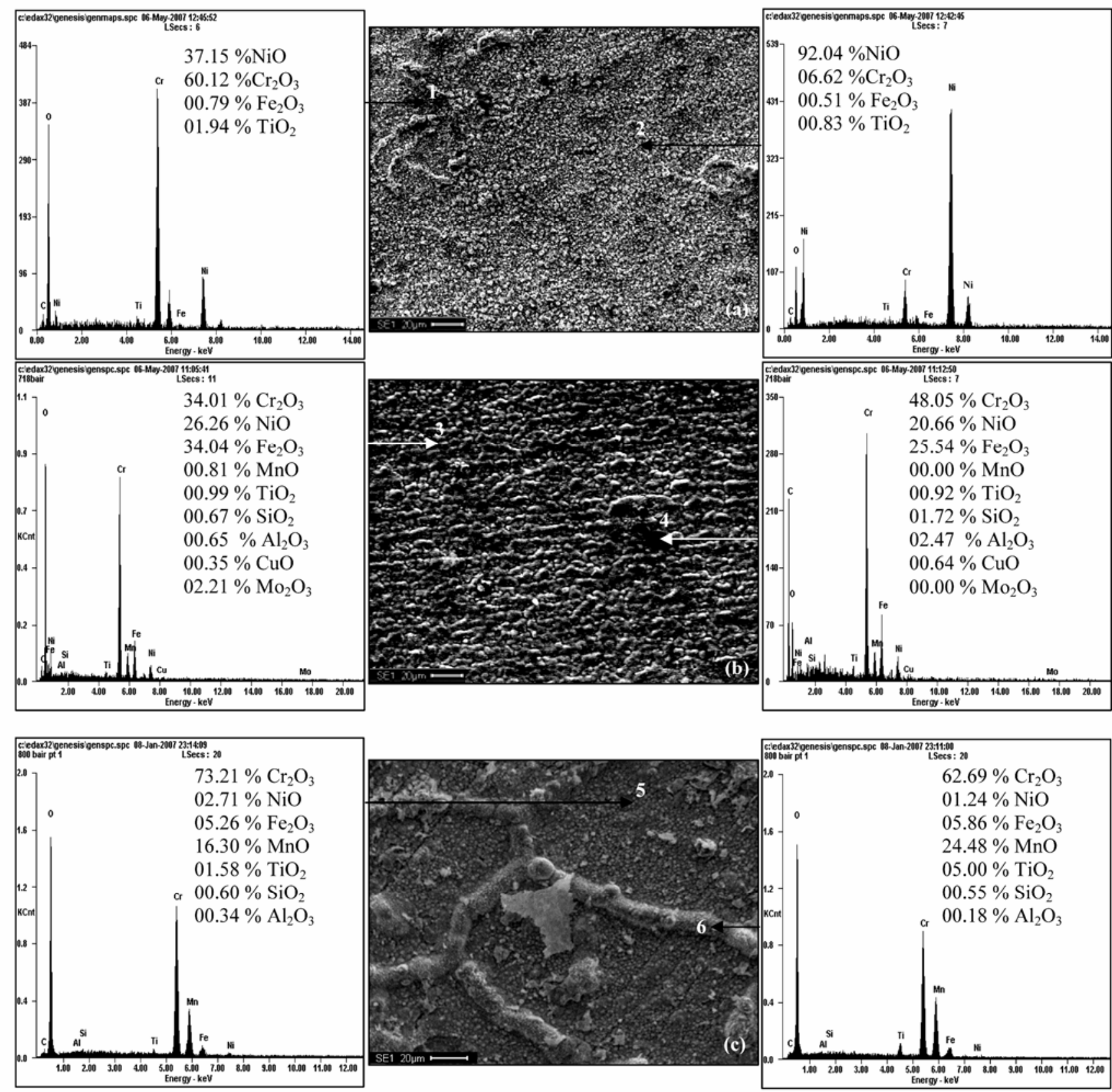

Figure 4. FE-SEM/EDAX analysis along with EDS spectrum for the superalloys subjected to cyclic oxidation in air at $900^{\circ} \mathrm{C}$ after 100 cycles: (a) Superni 75, (b) Superni 718 and (c) Superfer 800.

and (c)) show a massive scale with $\mathrm{NiO}, \mathrm{Cr}_{2} \mathrm{O}_{3}$ and $\mathrm{Fe}_{2} \mathrm{O}_{3}$ as major phases.

3.4b X-ray mapping: The hot corroded samples were cut across the cross-section and mounted in transoptic mounting resin, mirror-polished and gold coated to facilitate X-ray mapping by FE-SEM/EDAX of the different elements present across the scale. X-ray mapping analyses of the scale formed on the Superni 718 after hot corrosion in $\mathrm{Na}_{2} \mathrm{SO}_{4}-60 \% \mathrm{~V}_{2} \mathrm{O}_{5}$ environment at $900^{\circ} \mathrm{C}$ for 100 cycles (figure 6) reveals that the surface scale mainly consists of $\mathrm{Ni}$ and $\mathrm{Fe}$ in the upper most part of the scale, presence of oxygen in the top scale shows the formation of $\mathrm{NiO}$ and $\mathrm{Fe}_{2} \mathrm{O}_{3}$ layer. In the subscale region, there is a thick band of chromium $(\mathrm{Cr})$ which indicates the formation of relatively dense scale of $\mathrm{Cr}_{2} \mathrm{O}_{3}$, meagre amount of $\mathrm{S}$ is penetrated deep into the substrate.

\section{Discussion}

The weight change data for Superalloys subjected to oxidation and hot corrosion test in air and molten salt 

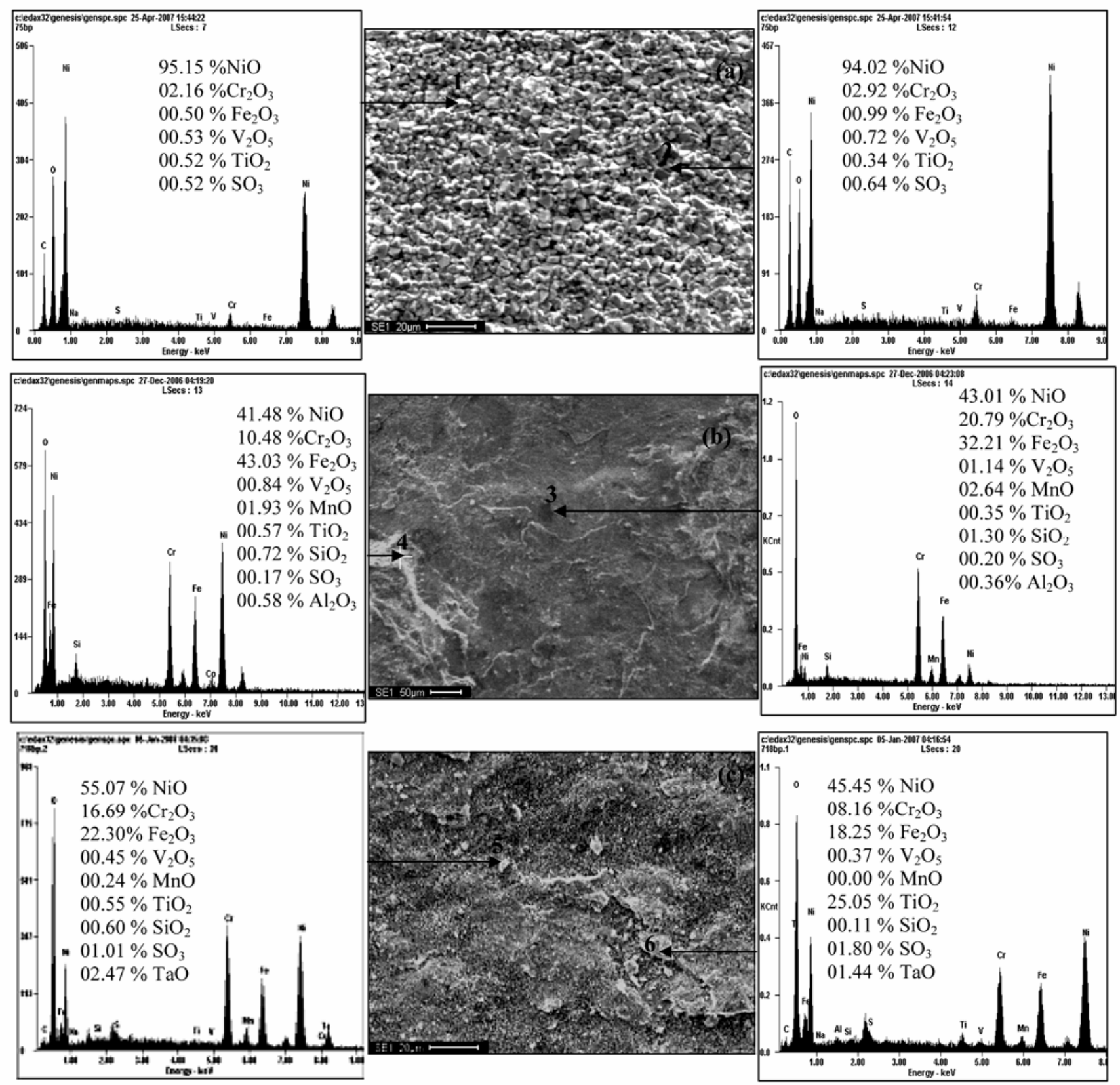

Figure 5. FE-SEM/EDAX analysis along with EDS spectrum for the superalloys subjected to cyclic hot corrosion in $\mathrm{Na}_{2} \mathrm{SO}_{4}-$ $60 \% \mathrm{~V}_{2} \mathrm{O}_{5}$ at $900^{\circ} \mathrm{C}$ after 100 cycles: (a) Superni 75, (b) Superfer $800 \mathrm{H}$ and (c) Superni 718 .

environment, respectively are plotted in figure 2 . It indicates that all air oxidized superalloys followed a parabolic rate law up to 100 cycles, whereas hot corroded superalloys show a larger increase in weight. Superni 75 followed the parabolic rate law whereas Superfer $800 \mathrm{H}$ deviates from parabolic law between 30 and 50 cycles, and for the remaining cycles it followed parabolic rate. A small deviation from the parabolic rate law might be due to cyclic scale growth. Superni 718 (figure 2) has shown a sputtering behaviour between 25 and 70 cycles; during these cycles, the corrosion products started falling out- side. The higher weight gain of the specimens during the first few cycles might be due to the rapid formation of oxides at the boundaries and within the open pores due to the penetration of the oxidizing species; afterwards, the subsequent increase in weight is gradual. Values of parabolic rate constant, $K_{\mathrm{p}}\left(10^{-10} \mathrm{~g}^{2} \mathrm{~cm}^{-4} \mathrm{~s}^{-1}\right)$, were obtained from slope of the linear regression fitted line and are tabulated in table 2. The nature of fit, parabolic rate law, for oxidation and hot corrosion of superalloys are shown in figure 2. The parabolic rate constant for the hot corroded superalloys is found to be greater than the air oxidized 
superalloy. The cumulative weight gain after 100 cycles of oxidation and hot corrosion at $900^{\circ} \mathrm{C}$ is shown in figure 3 . The overall weight gain of hot corroded superalloys, Superni 75 and Superfer $800 \mathrm{H}$, are $10 \cdot 4$ and $11.39 \mathrm{mg} / \mathrm{cm}^{2}$, respectively whereas, the overall weight gain for air oxidized superalloys, Superni 75, Superni 718 and Superfer $800 \mathrm{H}$ are $2.44,2.36$ and $2.86 \mathrm{mg} / \mathrm{cm}^{2}$, respectively (figure 3 ). The percentage increase in weight gains of superalloys, with respect to their air oxidized superalloys, due to hot corrosion for Superni 75 and Superfer $800 \mathrm{H}$ are $76.54 \%$ and $74.9 \%$, respectively. Poor corrosion resistance of superalloy, Superfer $800 \mathrm{H}$, is due to intense spallation and sputtering, which can be attributed to the severe strain developed as a result of $\mathrm{Fe}_{2} \mathrm{O}_{3}$ precipitation from the liquid phase and the inter-diffusion of intermediate layer of iron oxide. It is inferred that the superalloys are more prone to hot corrosion in molten salt environment. XRD analysis of hot corroded superalloy indicates the formation of $\mathrm{NiO}, \mathrm{Cr}_{2} \mathrm{O}_{3}$ and spinel as major phases.

Surface morphology and composition analysis of superalloys oxidized in air are shown in figures 4(a)-(c). The predominant phases formed on Superni 75 and Superni 718 are $\mathrm{NiO}, \mathrm{Cr}_{2} \mathrm{O}_{3}$ and $\mathrm{Fe}_{2} \mathrm{O}_{3}$, whereas Superfer $800 \mathrm{H}$ shows $\mathrm{Fe}_{2} \mathrm{O}_{3}, \mathrm{MnO}$ and $\mathrm{Cr}_{2} \mathrm{O}_{3}$ as major phases. EDAX analysis of the scale of Superni 75 (figure 4a) indicates the presence of $37 \cdot 15 \% \mathrm{NiO}$ at point 1 and

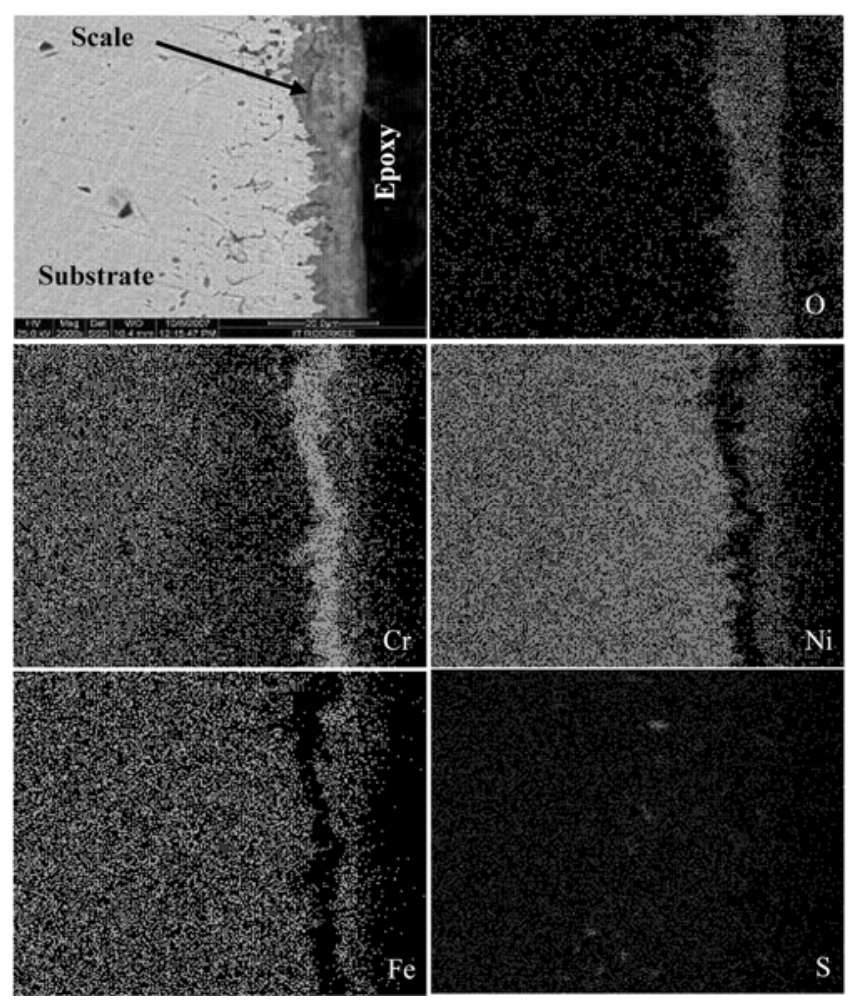

Figure 6. Composition image (SE) and X-ray mapping of the cross-section of the superalloy Superni 718 subjected to cyclic oxidation at $900^{\circ} \mathrm{C}$ in $\mathrm{Na}_{2} \mathrm{SO}_{4}-60 \% \mathrm{~V}_{2} \mathrm{O}_{5}$ after 100 cycles.
$92 \cdot 04 \% \mathrm{NiO}$ at point 2 as the main phases as indicated by strong peaks of EDS spectrum. Figure 4(b) at points 3 and 4 of Superni 718 oxidized at $900^{\circ} \mathrm{C}$ shows average of $41 \% \mathrm{Cr}_{2} \mathrm{O}_{3}, 23 \% \mathrm{NiO}$ and $30 \% \mathrm{Fe}_{2} \mathrm{O}_{3}$. The Superfer $800 \mathrm{H}$ (figure 4c) shows the formation of hemispherical shaped protrusion in entire oxidized surface along the scale grain boundaries, similar protrusion behaviour was reported in earlier literature (Choi et al 2002) during isothermal oxidation studies on plasma-sprayed $\mathrm{NiCrAlY}$ bond coat. The matrix mainly consists of $\mathrm{MnO}(16 \cdot 30 \%)$ and $\mathrm{Cr}_{2} \mathrm{O}_{3}(73 \cdot 21 \%)$, which is evident from the strong peaks of EDS spectrum at point 5 in figure $4 \mathrm{c}$. The protrusion mainly consists of $\mathrm{Cr}_{2} \mathrm{O}_{3}$ and $\mathrm{MnO}$ with $62 \cdot 69 \%$ and $24.48 \%$, respectively at the dark grey region, which is clearly visible from the strong peaks of EDS spectrum at point 6 (figure $4 \mathrm{c}$ ).

The surface micrographs of the hot corroded superalloys in molten salt $\left(\mathrm{Na}_{2} \mathrm{SO}_{4}-60 \% \mathrm{~V}_{2} \mathrm{O}_{5}\right)$ environment indicate the spalling behaviour of the scale as shown in figures 5(b) and (c). The EDAX analysis of the scale for the Superni 75 (figure 5a) indicates the presence of $95.15 \% \mathrm{NiO}$ at point 1 and $94.02 \% \mathrm{NiO}$ at point 2 as the main phases. In the case of Superfer $800 \mathrm{H}$ (figure 5b) substrate, the phases such as $\mathrm{NiO}, \mathrm{Fe}_{2} \mathrm{O}_{3}$ and $\mathrm{Cr}_{2} \mathrm{O}_{3}$ appear as predominant phases, with small amounts of $\mathrm{V}_{2} \mathrm{O}_{5}, \mathrm{MnO}$ and $\mathrm{SiO}_{2}$. It may be noticed that the percentage of $\mathrm{Cr}_{2} \mathrm{O}_{3}$ has increased in the black area of the scale. Also, Superni 718 (figure 5c) shows $\mathrm{NiO}, \mathrm{Cr}_{2} \mathrm{O}_{3}$ and $\mathrm{Fe}_{2} \mathrm{O}_{3}$ as principal phases along with very small percentages of $\mathrm{MnO}, \mathrm{SiO}_{2}, \mathrm{SO}_{3}$, and $\mathrm{V}_{2} \mathrm{O}_{5}$ as indicated by EDS spectrum. The amount of $\mathrm{Cr}_{2} \mathrm{O}_{3}$ varies from $16 \%$ to $8 \%$ at points 5 and 6 , respectively.

During initial cycles of hot corrosion studies, the corroding species reacts with the top surface of the superalloy substrate and starts migrating through the interface. As the oxidation proceeds, elements such as basically Fe and $\mathrm{Ni}$ were oxidized at the top surface and provides protection up to some extent, thereafter, chromium gets oxidized and forms a continuous $\mathrm{Cr}_{2} \mathrm{O}_{3}$ layer below the top oxide layer as revealed by X-ray mapping (figure 6). Chromia is the best oxide to resist hot corrosion in molten sulfates, as it preferentially reacts with $\mathrm{O}^{2-}$ in molten sulfates to form chromate. The chromate will stabilize the melt chemistry, and consequently prevent the dissolution of the protective oxide scale. The continuous thick band of $\mathrm{Cr}_{2} \mathrm{O}_{3}$ in the subscale will not allow any further transport of the oxidizing species and the metallic ions. The presence of these elements at the surface will decrease oxygen (Stott 1987) availability in the underlying alloy and favours the formation of most thermodynamically stable oxide $\left(\mathrm{Cr}_{2} \mathrm{O}_{3}\right)$. With the passage of time, further oxidation becomes negligible. This partially oxidized substrate provides protection to the whole substrate. $\mathrm{Cr}_{2} \mathrm{O}_{3}$ and $\mathrm{NiO}$ nuclei at the surface react to form $\mathrm{NiCr}_{2} \mathrm{O}_{4}$ spinel, as evident from the XRD analysis. So, the reaction is confined mainly to the top surface of the 
substrate. Some minor spalling of the oxide scale of superalloys especially on the edges and corners (Wang et al 2004) during cooling periods of the thermal cycles may be due to different values of thermal expansion coefficients of the substrate and oxide scales as known from the literature (Niranatlumpong et al 2000; Evans and Taylor 2001; Buta and Prakash 2005).

\section{Conclusions}

(I) All the superalloys are resistant to oxidation and hot corrosion at $900^{\circ} \mathrm{C}$ for 100 cycles.

(II) The parabolic rate constants $\left(K_{\mathrm{p}}\right)$ for the air oxidized Superni 75 , Superni 718 , and Superfer $800 \mathrm{H}$ superalloys are $0 \cdot 16,0 \cdot 147$ and $0 \cdot 237$, respectively.

(III) The $K_{\mathrm{p}}$ for the hot corrosion of superalloys is $2 \cdot 29$, $2 \cdot 1$ and 4.312 , respectively.

(IV) Superalloy, Superni 75, has higher oxidation and hot corrosion resistance properties as compared to other two superalloys. These superalloys are found to be more resistant to oxidation as compared to that of hot corrosion.

(V) The formation of protective oxide scales such as $\mathrm{NiO}, \mathrm{Cr}_{2} \mathrm{O}_{3}$ and $\mathrm{Fe}_{2} \mathrm{O}_{3}$ is responsible for imparting resistance against high temperature oxidation and hot corrosion of superalloys investigated in the present work.

\section{Acknowledgement}

The authors are very much thankful to Mr K Ramesh, General Manager (Commercial), and Mr I S N Murthy,
Mishra Dhatu Nigam Limited, Hyderabad (India), for providing the Superalloys.

\section{References}

Buta S S and Prakash S 2005 Oxid. Met. 63241

Bettge D, Osterle W and Ziebs J 1995 Z. Metalkd 86190

Chen H, Chen W, Mukherji D, Wahi R P and Wever H 1995 Z. Metalkd 86423

Choi H, Yoon B, Kim H and Lee C 2002 Surf. Coat. Technol. 150297

Deb D, Ramakrishna S Iyer and Radhakrishnan V M A 1996 Mater. Letts 2919

Esmaeili S, Engler-Pinto Jr C C, Ilschner B and Rezai-Aria F 1995 Scr. Metall. Mater. 33777

Evans H E and Taylor M P 2001 Oxid. Met. 5517

Hejwowski T 2006 Vacuum 801386

Gurrappa I 1999 Oxid. Met. 51353

Li J and Wahi R P 1995 Acta Metall. Mater. 43507

Maledi N B, Potgieter J H, Sephton M, Cornish L A, Chown L and Suss R 2006 J. S. Afr. Inst. Min. Metall. 8190

Niranatlumpong P, Ponton C B and Evans H E 2000 Oxid. Met. 53241

Otero E, Pardo A, Perez F J, Atlvarez J F and Utrilla M V 1996 Surf. Coat. Technol. 85156

Rocca E, Steinmetz P and Moliere M 2003 Trans. ASME 125664

Sidhu T S, Prakash S and Agrawal R D 2006 Acta Mater. 54773

Stott F H 1987 Rep. Prog. Phys. 50861

Stringer J 1976 Final Report EOAD-TR-76-05 (AD A031363)

Wang Q M, Wu Y N, Ke P L, Cao H T, Gong J, Sun C and Wen L S 2004 Surf. Coat. Technol. 186389

Wang Y, Mukherji D, Chen W, Kuttner T, Wahi R P and Wever H Z 1995 Metalkd 86365

Zhang J S, Hu Z Q, Murata Y, Morinaga M and Yukawa Y 1993 Met. Trans. A4 2443 